\title{
Acute Hepatopancreases Necrosis Diseases (AHPND) as Challenging Threat in Shrimp
}

\author{
Jahangir Ahmed ${ }^{1}$ (D), Mohd Hashim Khan ${ }^{1}$ (D), Sneha Unnikrishnan ${ }^{1}$ (D), \\ Karthikeyan Ramalingam 1,* (D) \\ 1 School of Life Sciences, B.S. Abdur Rahman Crescent Institute of Science and Technology, Chennai, Tamil Nadu, India \\ * Correspondence: karthikeyan.sls@crescent.education;
}

Scopus Author ID 43961552400

Received: 24.02.2021; Revised: 5.04.2021; Accepted: 8.04.2021; Published: 26.04.2021

\begin{abstract}
White feces syndrome (WFS) is an emerging problem for penaeid shrimp farming industries in South East Asia countries. Outbreaks began in cultivated shrimp Penaeus (Penaeus) monodon, and Penaeus (Litopenaeus) vannamei and spread progressively worldwide, although the disease's cause was unknown. In 2011 a case definition for AHPND (as acute hepatopancreatic necrosis diseases) and white fecal syndrome (WFS) were reported. The presence of white feces floating on water and clinical symptoms include pale empty gut region, reduced growth, movable shell, and black discoloration. The pacific white shrimp, Litopenaeus vannamei, with the major shrimp cultivable species globally, is currently in danger by a severe disease- WFS, which causes serious losses worldwide. It has been confirmed that the causative agent of WFS/AHPND is a bacterium that is a pathogen - probably Vibrio parahaemolyticus. This bacterium currently reported has acquired plasmids that encode lethal binary toxins PirA/PirB causing rapid death of infected shrimp. Additionally, this plasmid acquired some virulence factor which is directly related to pathogenicity. Further rapid diagnostic tests for early detection of WFS/AHPND pathogens will promote the production of hatchery and pond maintenance and contribute to the long-term explication of the disease's various aspects.
\end{abstract}

Keywords: shrimp; Vibrio parahaemolyticus; plasmids; PirA/PirB; acute hepatopancreatic necrosis syndrome; (AHPND).

(C) 2021 by the authors. This article is an open-access article distributed under the terms and conditions of the Creative Commons Attribution (CC BY) license (https://creativecommons.org/licenses/by/4.0/).

\section{Introduction}

Aquaculture business plays a significant role in the worldwide economy and provides huge job opportunities and revenue. The demand increases over the years and depends heavily on human consumption. Among the various aquaculture industries, the crustacean industry has grown rapidly in recent years due to crustaceans' growing market demands worldwide. Amongst the various aquaculture types, the shrimp culture industry grew very fast in Southeast Asian countries. India ranks fifth among big shrimp manufacturers in Asia, followed by China, Thailand, Indonesia, and Vietnam [1-3].

Marine animals prove to different diseases caused by viruses, bacteria, fungi, and protozoans. The shrimp industry suffered from severe infectious diseases previously, such as Infected Hypodermal and Hematopiotic virus, Taura Syndrome Virus, Hematopancreatic parvovirus, White spot Syndrome Virus, and Yellow head Virus [4-6]. The WFS/APHND effects on shrimp cultures with economic impacts of the pandemics caused by these pathogens have been severe in countries where shrimp farming is a major industry [7-9]. Disease incidences will significantly reduce the economic growth and production of the aquaculture 
industry. The growth and transportation of the penaeid shrimp culture industry worldwide increased over the last two decades with the multiple incidences of infectious pathogens. Hence countries imposed trade restrictions to prevent WFS/AHPND disease incidence and strengthened the policies [10-12]. WFS initially named early mortality syndrome (EMS) because after freshly stocked white feces appears within 30 days, the mortality rate can be up to $100 \%$. WFS/AHPND-causing V. parahaemolyticus damages shrimp but does not affect humans due to properties of thermolabile hemolysin (TLH), [13-15].

The specific plasmid present in pathogenic species of Vibrio encodes pirA/pirB genes, the virulence factors of WFS/AHPND, which are toxins PirA/PirB (photorhabdus insectrelated). Pathogenic effects of WFS/AHPND include atrophy and lesion production with a low bacterial population and the presence of PirA and PirB toxins in protein lysates observed in the intestine, hepatopancreas, and shrimp haemolymph. Within 6 hours, shrimp hepatopancreas sloughing shows due to high-level PirB concentration. Post-infection in the hepatopancreas showed PirA appearance [16].

Thereafter, Non $V$. parahaemolyticus species possess a strain similar to $V$. campbelli and $V$. harveyi, suggesting that these toxin genes can be passed to different Vibrio species and found this plasmid are self transmissible. V. parahaemolyticus AHPND strains have been found to carry tetB gene encoding tetracycline resistance gene, and $V$. campbelli from China has been found to carry several antibiotics resistance genes [17-21]. So, if new methods cannot be discovered to control these diseases, traditional methods result fail to compensate in WFS/AHPNS controls and treatment of shrimp diseases. This review includes important findings that could help and serve as investigations and recommendations for further research and studies on WFS/AHPND or other shrimp's diseases.

\section{Epidemiology}

The White shrimp (L. vannamei) benefits of being able to grow as fast as tiger shrimp (3 gram/week), and salinity range (0.5-45 ppt), protein requirement (20-35\%) the tiger shrimp better feed conversion ratio (1.2-1.6) and a higher stocking density [1, 22,23]. There is $7 \%$ loss occurs shrimp culture in Thailand, especially in that coastal area. This disease was recorded in 2013 from the Western Hemisphere and Mexico and incurred an economic loss of some USD 118 million in part of these regions [24].

Table 1. Represent the loss and production of shrimps in the Asian country.

\begin{tabular}{|c|c|c|c|c|}
\hline Shrimp species production & Loss & Country & Year & References \\
\hline $\begin{array}{l}\text { Litopenaeus vannamei (White shrimp), } \\
488,002-488,019 \text { tons }(100.83 \%, 2016) \text {, in } \\
\text { targeted increase which is } 19.86 \% \text { as compare } \\
\text { to } 2015 \text {. }\end{array}$ & $11.6 \%$ & Indonesia & $2015-16$ & {$[1,27]$} \\
\hline $\begin{array}{l}800,000 \text { tons Litopenaeus vannamei (White } \\
\text { shrimp) and Penaeus monodon (tiger shrimp) }\end{array}$ & $11.6 \%$ & Indonesia & 2018 & {$[1,27]$} \\
\hline Litopenaeus vannamei and Penaeus monodon & $570000-7200000$ & $\begin{array}{l}\text { Asian country } \\
\text { economic loss } \\
\text { USD, especially } \\
\text { in (Vietnam) }\end{array}$ & $2011-12$ & [1] \\
\hline Litopenaeus vannamei and Penaeus monodon & $\begin{array}{c}\text { Mass mortality decreases } \\
70000 \text { and } 40000-30000 \\
\text { tons }\end{array}$ & Asian countries & $2010-11$ & [24] \\
\hline $\begin{array}{l}\text { Litopenaeus vannamei and Penaeus, monodon } \\
65100 \text { to over } 121208 \text { hectare. }\end{array}$ & $10.9 \%$ & India & $\begin{array}{c}\text { 1990-91 to } \\
2011-12 \\
\text { (SEAI,2012) }\end{array}$ & {$[1,25,27]$} \\
\hline
\end{tabular}


Shrimps culture added a volume of $22 \%$ of 862021 tons and $49 \%$ of Rs. 16597 of India's total exports of marine products in 2011-12 (SEAI, 2012). The farmers bred Penaeus monodon for the first time and then moved to Litopenaeus vannamei, and their earnings are growing $[1,25]$. Large numbers of shrimp farms populated the Indian coastline, and a massive infrastructure was built to support shrimp aquaculture. During this period, government agencies have implemented many schemes to encourage shrimp farming (CIBA 2009). It was until 1994, viral diseases are affecting the shrimp culture, and from 2008 onward, vibrio bacteria ( $V$. parahaemolyticus, $V$. proteolyticus, $V$. alginolyticus) were identified have great losses to the shrimp culture industry showns in (table 1) [26]. In India to date, the only available peerreviewed for assessing Vibrio sp. plasmids attains toxin, and how mortality is due to WFS/AHPND is by a histological process in L. vennameai.

\section{Pathogenesis of $V$. parahaemolyticus}

Vibrio parahaemolyticus is the food-borne pathogen causing diarrhea primarily due to uncooked seafood consumption, including crab, shrimp, shellfish, lobster, fish, and oysters. While infecting, $V$. parahaemolyticus uses adhesion factors to bind the host cell to the fibronectin and phosphatidic acid, injecting various toxins into the cytoplasm, causing cytotoxicity. Two main virulence factors of $V$. parahaemolyticus are thermostable direct hemolysin (TDH) and TDH-related hemolysin (TRH), which is directly linked to its pathogenicity in (Table 2). It is one of the hemolytic processes that are independent of lipid rafts. TDH binds to the membranes of red blood cells on host cells, creating a pore on the membrane's surface that eventually contributes to cell colloid permeation. The other enzymatic function is its cytotoxicity; TDH triggers toxicity of cells and forms a channel in the cell membrane that induces increases in the concentration of extracellular a $\mathrm{Cl}^{-}$and $\mathrm{Ca}^{2+}$ secretion when osmotic pressure exceeds the upper limit resulting in cell expansions and even death [15] and induces red blood cell lysis as well. TLH is distributed across V. parahaemolyticus clinical and environmental strains. The gene is significantly upregulated during simulated conditions of intestinal infection. Wang et al. proved this protein activity on (Hela, Changliver, and RAW264.7 cell lines). It showed signs of extreme cytotoxicity when treated with the purified TLH protein, and its effects were dependent on dosage and time [28]. The toxin-mediated infection cycle had to be unraveled at the cellular level. In binary PirABtoxins, PirA promotes the target-specific identification of toxins by binding to certain ligands on the cell membrane and receptors (e.g., monosaccharides such as $\mathrm{N}$-acetylgalactosamine (GalNAC) and oligosaccharides), while PirB toxin (containing N-terminal domain, PirBN domain, and Cterminal domain, PirBC domain) is mainly responsible for cell death by pores and for proteinprotein and protein-ligand interactions. Also, toxins PirA and PirBtogether form a complex and function synergistically, leading to improved toxicity of PirAB toxins to laboratory animals.

Table 2. List of some known virulence factors of $V$. parahaemolyticus.

\begin{tabular}{l|l|l|l} 
Effectors & Gene & Biological activity & Effects on host cells \\
\hline Toxins & & & \\
\hline TDH & thh & Form pores on cell & Cytotoxicity and enterotoxicity \\
\hline TRH & trh & Form pores on cell & Cytotoxicity and enterotoxicity \\
\hline TLH & th & Hemolysin activity or? & Cytotoxicity and?
\end{tabular}

In addition to that PirAB toxins bind to the digestive tract of epithelial cells, cause necrosis, and destroy the cellular structure, including a nucleus, mitochondria, junctional 
complex, rough endoplasmic reticulum (RER), etc., resulting in the subsequent death of challenged brine shrimp larvae [29, 30].

\subsection{V. parahaemolyticus $A H P N D$ and V. compbelli $\left(V P_{A H P N D}\right.$ and $\left.V C_{A P H N D}\right)$.}

Recent research found that VPAHPND possesses a plasmid that produces a deadly toxin PirAB (constituted by PirA and PirB), homologous to the binary toxin identified Photorhabdus insect-related (Pir). Vibrio species' virulent strains also contain pVA 1 plasmid $(63-70 \mathrm{~kb})$, encoding the binary PirA and PirB toxins. The plasmid $\mathrm{pVA}_{1}$ also carries a cluster of genes linked to the conjugative transmission. Comparison of full genomes found that the pirABbearing plasmids in the two strains were strongly homologous, and both shared strong homologies with plasmid $\mathrm{pVA}_{1}$, the recorded plasmid carrying pirAB. Conjugation and DNAuptake genes have been detected on plasmids of the $\mathrm{pVA}_{1}$ type and the host chromosomes, respectively, promoting the propagation of pirAB [31, 42]. This plasmid may theoretically be transmitted not only to $V$. parahaemolyticus strains but also to various bacterial species as well. PirAB has also been confirmed to occur in harveyi-like Vibrio (one isolate from Vietnam) [17], $V$. owensii (one isolate from China), and V. compbelli (one isolates from China and Latin America) [19, 33].

\subsection{Clinical sign and histopathology.}

Two essential cultivated shrimps, such as black tiger shrimp (P. monodon) and American white leg shrimp (L. vannamei), had identified this disease in Southeast Asia. Under healthy conditions, the shrimp stomach full, large pigmented hepatopancreases and full midgut shown in (figure 1A). The affected shrimp sunk to the bottom of the pool and died there. Melanization is due to hepatopancreatic discoloration caused by loss of pigmentation of the connective and epithelial tissues and black coloration. The affected hepatopancreas is not quickly squashed by the palm, which is possibly caused by decreased connective tissue or hemocyte aggregation [24]. Histological observation showed degeneration and incapacitation of tubules epithelium cells in hepatopancreases due to expansion or exfoliation into the intestine (figure 1B). The loss to the intestinal villi is a sign of a bacterial infection that is damaging shows white shrimp intestine. Exposure of affected gastrointestinal villi cells indicates antigen attachment by bacteria and will be signed as empty stomach and gut infection in shrimp [1].
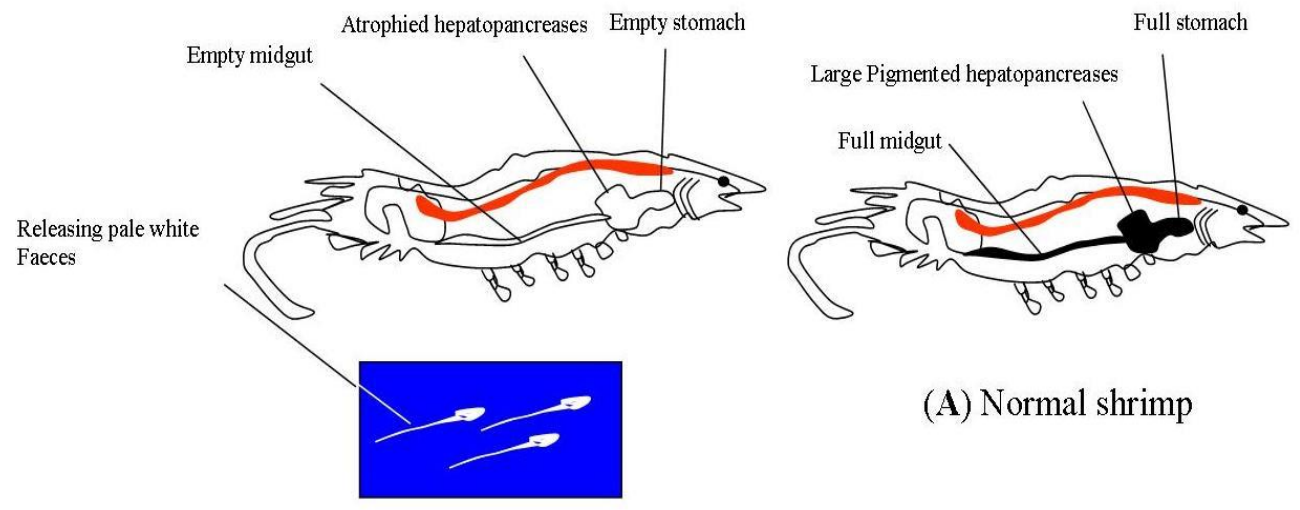

(B) APHND effected Shrimp

Figure 1. [A] Normal Penaeus vannamei shrimp compare; [B] Showing gross signs are influenced by AHPND. 


\subsection{The AHPND-related plasmid and PirA/B toxins.}

While some $V$. parahaemolyticus strains were known as AHPND causative agents, not all strains can cause the disease. This sequenced $V$. parahaemolyticus genomes and plasmids isolated from AHPND-infected shrimps and grown-out ponds, and found that AHPND was triggered only by $V$. parahaemolyticus strains that had extra-chromosomal plasmid encoding binary toxins PirA and PirB. The plasmid pVA1 includes genes for conjugative transfer and plasmid mobilization, making the plasmid auto-transmissible [34]. The plasmid also carries a post-segregational killing system (PSK) pndA, ensuring that the plasmid is still inherited [31]. Earlier, studies reported nine strains, all belonging to V. parahaemolyticus [35-38]. In Northern Vietnam, an AHPND-causing strain V. campbellii was found in 2015 [17]. All these AHPNDpathogenic $V$. parahaemolyticus and as well as $V$. campbellii harbors plasmid containing the PirAB genes that encoding PirAB toxins [39]. Novel strain SH-14, also found to contain plasmid of this form, was isolated from shrimp HP in Shanghai, China [40-41]. Liu et al. 2018 indicated that PirAB toxic genes on the $V$. owensii $\mathrm{SH}-14$ plasmid could induce signs consistent with shrimp AHPND, and understanding the spread of pirAB through plasmid among Vibrio's members in the natural environment [42]. Until now, Thailand, Mexico, China, Vietnam, and South America have identified $V$. parahaemolyticus strains containing plasmids with the genes for hypothetical virulence. However, there is genetic variability in plasmid sequences, which has resulted in a Mexican type description, characterized by an insertion of 4,243bp Tn3-like transposon and a 9bp small sequence repeat (SSR), both features being absent in Asian types. All plasmids however, include the toxin genes and a group of transposase-coding sequences consistent with horizontal gene transfer [43]. Sawabe et al. concluded that HGT could occur between sisters species such as $V$. cholerae and $V$. mimicus (Cholerae clade) or $V$. harveyi and V. campbellii (Harveyi clade) within the genus Vibrio [44]. To date, no proof of HGT among species has been found belonging to distantly related clades. The presence of VPAHPND has recently been observed in $\mathrm{V}$. parahaemolyticus strains and in other similar species, in particular: V.herveyi, Vowensii, and V. campbellii, all species belong to Harveyi clade. It is the reason why this clade is known as the AHPND pathogens. Vibrio species in the Orientalis clade are not disease-causing agents, except for $V$. tubiashii and $V$. sinaloensis associated with bivalve and fish mortality. There is, in fact, no record of crustacean pathogens within this clade. Restrepo et al. identified a new species of the Vibrio, Vibrio punensis sp. nov. Strain BA55, a member of the Orientalis clade and closely related to $V$. orientalis and $V$. hepatarius. $V$. punensis sp. nov. Strain BA55 carries the toxin gene-containing plasmid shown to be the cause of AHPND in shrimp [45]. The cell damage this toxin can inflict also describes how $V$. parahaemolyticus, which initially only colonizes the stomach of the shrimp, can enter the hepatopancreas. More analysis of $\mathrm{pVA}_{1}$ plasmid and PirAB toxin found that when nonAHPND strains of $V$. parahaemolyticus were converted with the plasmid containing PirAB, they were capable of triggering AHPND-like clinical signs and $100 \%$ shrimp mortality when a mutated strain of AHPND-causing $V$. parahaemolyticus missing the pirAB genes did not induce AHPND. Furthermore, the AHPND- strain and the non-AHPND strain of $V$. parahaemolyticus from the same contaminated shrimp; the AHPND- strain (VPE61) harbored an estimated size $(69 \mathrm{kbp})$ virulence plasmid, while the non-AHPND strain of $V$. parahaemolyticus (VP2HP) had $183 \mathrm{~kb}$ of the plasmid (figure 2). All the genes present in the $69 \mathrm{~kb}$ plasmid were used in the $183 \mathrm{~kb}$ plasmid except that it lacked the complete $3.4 \mathrm{~kb}$ PirA / PirB transposon portion [46, 29]. 


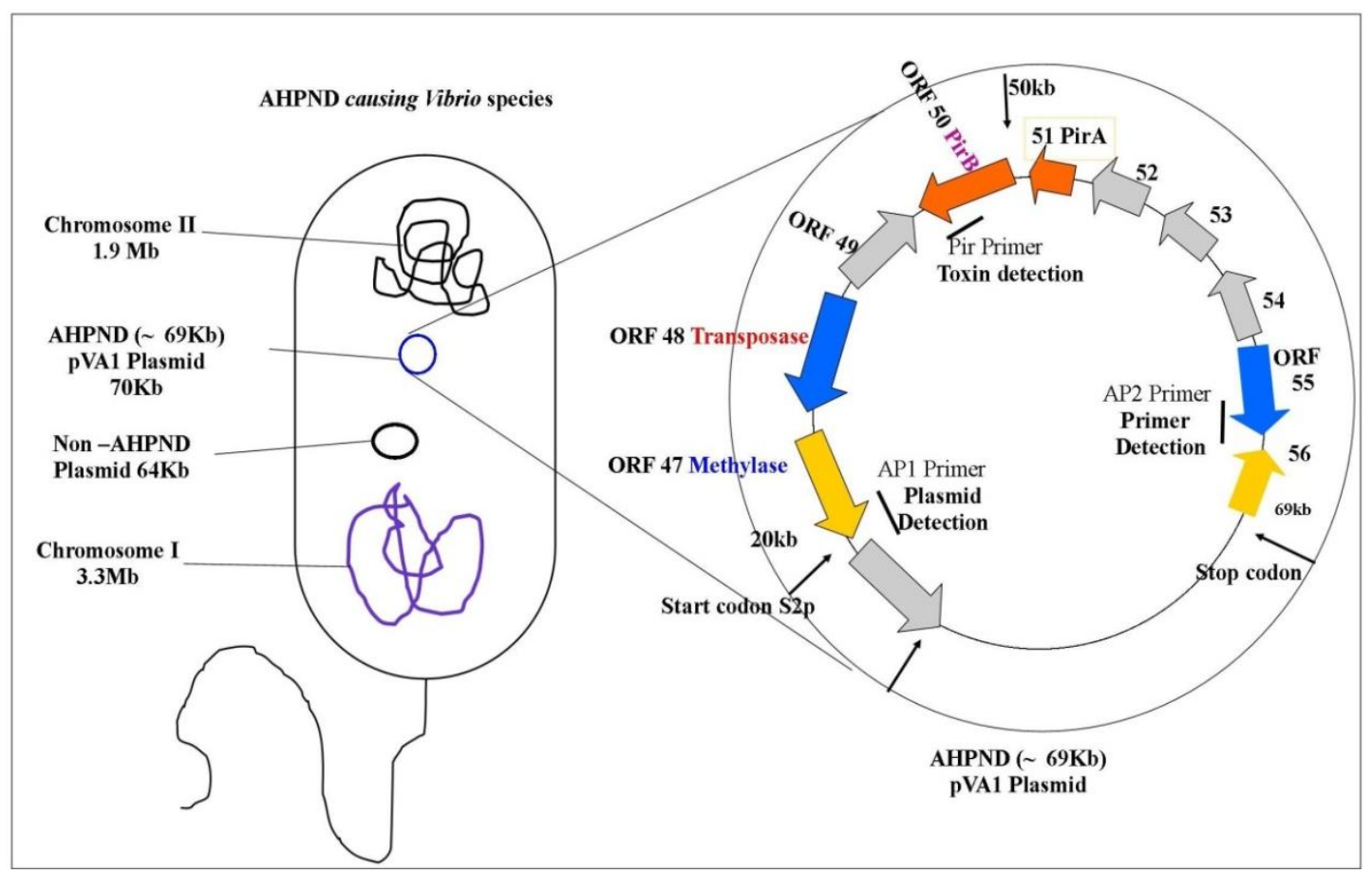

Figure 2. Acquired plasmid in vibrio Parahaemolyticus caused acute hepatopancreatic necrosis disease (AHPND). The distinction between the $V$. parahaemolyticus AHPND causing and non-AHPND-causing strains is the presence of a single $69 \mathrm{~kb} \mathrm{pVA} 1$ plasmid. The sites in the plasmid $\mathrm{pVA}_{1}$ of the methylase (in arrows), transposase (in arrows), shown, and PirAB toxin genes. Parts amplified on $\mathrm{pVA}_{1}$ plasmid by the common primers AP1, AP2, and AP3 are also shown.

\subsection{Diseases Diagnosis in shrimp.}

AHPND can be avoided by early identification of $V$. parahaemolyticus either in the shrimp itself or in the cultural environment. Since the first to be detected and described a decade earlier, the virulent $\mathrm{pVA}_{1}$ plasmid that harbors the binary PirAB toxin, both of these toxin genes were used as essential markers for AHPND diagnostics [47]. The key and special histological features of AHPND in the early to middle stage of the disease are the sloughings and significant rounding of epithelial cells of hepatopancreatic tubules without observable causative pathogen. These characteristics are important for diagnosis, and it is advised to gather and examine 10 or more shrimp specimens from any infected pond to ensure that at least one specimen is at this stage of the disease. This is the reasonable approach since the disorder is characterized at the initial stages of AHPND by medial to distal instability of B (blisterlike), F (fibrillar), and R (resorptive) cells, conspicuous karyomegaly, and loss of mitotic involvement in E (embryonic) cells [48]. Suspected organisms such as shrimps, sediments, or feeds should be labeled with Davidson's AFA fixative for approximately 1-2 days for light microscopy analysis and stained with hematoxylin and eosin. In addition to light microscopy, scanning electron microscopy (SEM) and transmission electron microscopy (TEM) can be used to examine samples [10]. Many of the currently available AHPND diagnostic kits are PCR-based, which use either traditional PCR samples or PCR techniques in real-time, although such kits take time and need costly equipment. The researchers have recently concentrated on designing AHPND detection systems for diagnostic laboratories that are less time-intensive with high throughput and improved sensitivity and specificity. For example, for fast, high-throughput detection of AHPND, a multiplex real-time PCR (SYBR and Taqman strategy) using primers targeting pirA, pirB, shrimp 18S, and bacterial 16S genes was developed. Nevertheless, as most shrimp farmers are not economical with PCR- kits and thermal cyclers, alternative visual identification 
methods use fluorescence- assays such as the recombinase polymerase (RPA) assay was introduced in shrimp farms for on-site diagnosis [49]. Also, a new method called loop-mediated isothermal amplification (LAMP), DNA may be amplified' under isothermal conditions by a new method in just $1 \mathrm{~h}$, and LAMP creates in a large number of the stem-loop amplicon of equal lengths from a small collection of a template. This detection process uses loop-mediated isothermal amplification (LAMP) and an ssDNA-labeled nanogold probe (AuNP) to identify pirA genes in shrimp and pond sediments within an hour. In the same year, another team of researchers created a LAMP-based detection system that used a water bath rather than a pricey thermocycler; this technique detected pirAB-like genes in $V$. parahaemolyticus strains triggering AHPND with greater specificity and efficiency than traditional PCR methods. Subsequently, the same group developed a simpler and more precise approach for diagnosing diseases related to shrimp in conjugation with APHND by PCR-DNA chromatography process in which multiplex PCR items are visualized using a single-strand-tag hybridized chromatographic printed array strip [50-52].

\subsection{Shrimp immunological response against infections.}

Shrimps exhibit an innate immune response to bacterial infections. This reaction involves cytokines, melanization, the mechanism of prophenoloxidase (proPO), thioredoxin (trx), ferritin (fer), pattern recognition proteins, antioxidants, antimicrobial peptides, and lysosomal enzymes, with antimicrobial peptides being investigated extensively in the pathogenesis of AHPND in particular. AHPND-infected shrimp hemocyte and stomach transcriptomics experiments have produced several differentially expressed immune genes in various immune pathways, including penaeidins, crustins, serpins, lectins, and antilipopolysaccharides factors [53,54]. There are short antimicrobial polypeptide known as the antilipopolysaccharides factor (ALF) works on bacteria, fungi, and virus in shrimp's immune system. In another study, (L. vannamei) LvALF and PirAB toxin molecular modeling and docking research found that LvALF interacts with PirB toxin via its LPS-binding sites and that LvALF's knockdown followed by the PirAB toxin challenge resulted in increased mortality in L. vannamei $[55,56]$. The single-WAP domain-containing protein (SWD) is a type III antimicrobial crusting peptide that functions as a subtilisin proteinase inhibitor in $L$. vanname $i$ and was also upregulated in AHPND-infected shrimp hemocytes [57]. Haemocyanin is a protein that serves to store and transport oxygen in the hemolymph of shrimps. Under healthy conditions, the shrimp stomach cell, intestine villi and mucus covering are comprised of normal and a lumen that includes a harmless population of gut microbiota in (figure $3 \mathrm{~A}$ ). Research however, (figure 3B) indicates that it also demonstrates an antibacterial immune response in L. vannamei, precisely a $V$. parahaemolyticus accumulation [30]. This has also been shown that AHPND-causing $V$. parahaemolyticus stimulates the Rho-signaling pathway in L. vannamei and is believed to inhibit cell adhesion molecules epithelial cells of the stomach and promote the movement of toxins and bacteria from the stomach to hepatopancreas during AHPND infection. Kumar et al. (2020) reported that bile acid was observed to promote the release of Pir $\mathrm{AB}$ toxin, while bile acid levels decreased in L. vannamei stomach caused AHPND induced mortality rates to decrease [34]. In recent years, substantial work has been carried out into the function of microRNAs (small non-coding RNAs) in disease progression. While the direct reaction of shrimp hepatopancreatic tubule epithelial cells has not yet been examined, a comparative transcriptomic study of shrimp (L. vannamei) hemocytes infected AHPND, and non-AHPND bacteria was used to categorize 12 dysregulated micro-RNA 
candidates [58]. These micro-RNAs were involved in the immune system, apoptosis pathways, and metabolism.

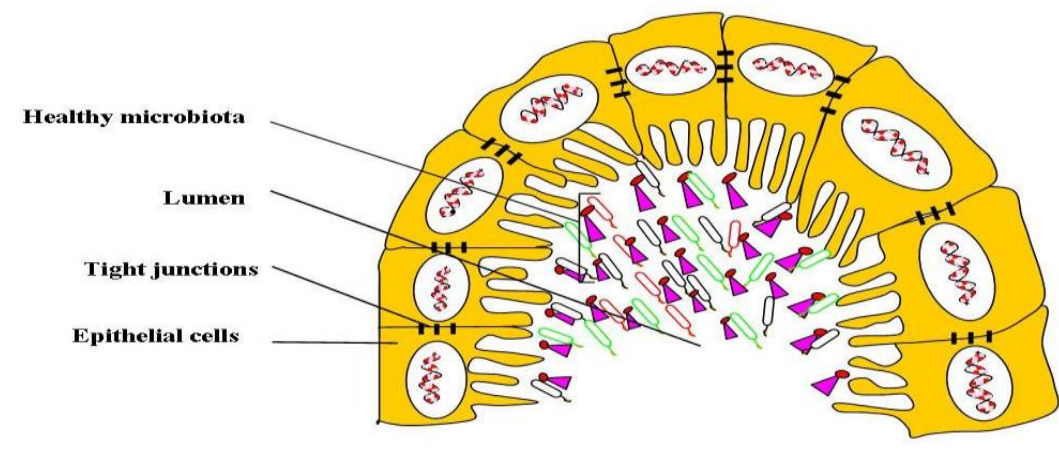

[A]. Healthy bacteria and Hepatopancreatic cell

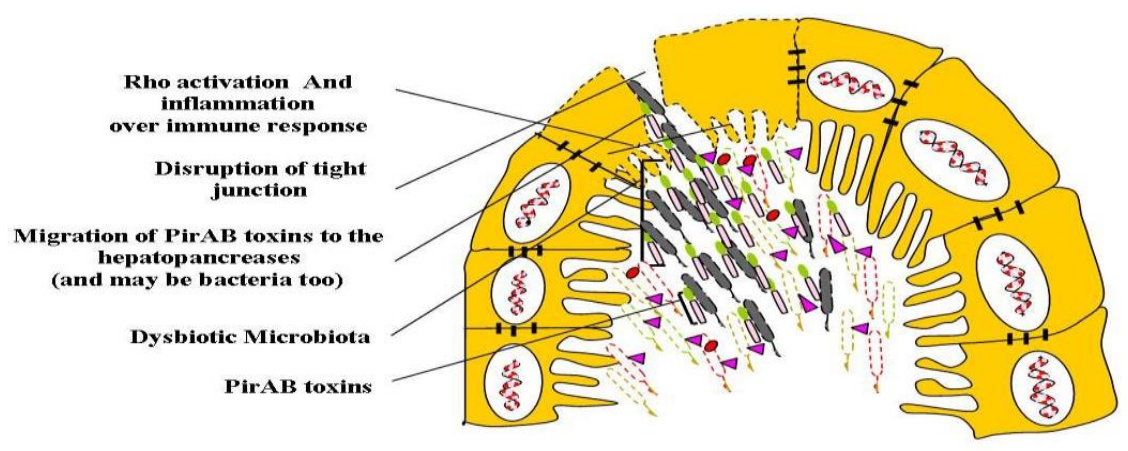

[B]. Migration of PirAB toxin into hepatopancreatic cell

Figure 3. The figure above shows the acute hepatopancreatic necrosis disease (AHPND) pathogenesis process. [A] Under healthy conditions, the shrimp stomach is comprised of epithelial cells, a chitinous layer/mucus covering, and a lumen that includes a harmless population of gut microbiota. The shrimp gut microbiota and metabolites cells release (circles and triangles), which aid in the normal functioning of the digestive processes. [B] AHPND-causing Vibrio parahaemolyticus reaches the shrimp intestine by an oral route and allows the previously healthy gut microbiota to become dysbiotic, introducing PirAB toxins into the lumen following proliferation and invasion by $V$. parahaemolyticus. It triggers an immune response and activation of Rho pathway. Rho-signaling pathway activation disrupts the tight junctions between the stomach's epithelial cells, causing intercellular spaces to form. Via the intracellular openings, the PirAB toxins and V. parahaemolyticus bacteria migrate into the hepatopancreas

\subsection{AHPND-infected shrimp treatments and therapies.}

Currently, there have been significant advances in successful AHPND therapies in addition to advancements in the diagnosis. In general, antibiotics are used to cure bacterial diseases; however, there is a danger in shrimp aquaculture that the use of antibiotics may lead to drug resistance in bacteria that threatens shrimp and human beings. Therefore, in the diagnosis of AHPND infection, plant-derived compounds, phages, nanoparticles, and recombinant immune-related proteins with antibacterial activity should be favored. Plant extracts with antibacterial properties have been shown to provide defense against AHPNDcausing bacteria when used as feed additives in the shrimp diet. For instance, $P$. vannamei provided feed supplemented with a combination of essential oils from ten completely different plants showed no gross clinical signs of AHPND ten days after $V$. parahaemolyticus infection $[59,60]$. The most widely used way of treating outbreaks caused by Vibrio bacteria is applying antibiotics in aquaculture; however, antibiotic resistance is a major concern along with the 
potential introduction of the medication into the environment. The effective approach for preventing and treating vibriosis in aquaculture is the use of lytic phages called phage/bacteriophage therapy. Lomeli-Ortega and Martinez-Diaz (2014) found that administering lytic phages A3S and Vp $16 \mathrm{~h}$ post-infection was successful in reducing mortality. L. Vannamei from $V$. parahaemolyticus. Administration of lytic phages greater than 6 hpi (Hours post infections) decreases the progression of mortality and disease [61]. This research was performed under gnotobiotic conditions, and more studies on the efficiency of phage therapy are required to develop a model to analyze the different external factors such as the nature of the water and volume of organic matter. A phage experimental therapy in $P$. vannamei recently demonstrated important safety and survival against the $V$. parahaemolyticus AHPND of challenge tests [62]. The use of probiotics to prevent certain bacterial infections in shrimps has been successful and has increased aquaculture water quality [63]. Purple nonsulfur bacteria (PNSB) are widespread in the aquatic ecosystem and are commonly found in shrimp farms where other marine species have grown better in culture [64]. There is also very little information currently available about the anti-Vibrio compounds developed by Purple non-sulfur bacteria (PNSB). Bioactive compounds were described and biosynthetically developed against $V$. fischeri and $V$. harveyi by Rhodobacter spihaeroides [65]. A recent study revealed that a potential biocontrol agent against AHPND was found to exhibit probiotic bacteria CDA22 and CDM8, which were isolated from P. vannamei hindgut. For instance, CDA22 and CD8 decrease the number of Pir A gene copies responsible for the $V$. parahaemolyticus virulence [66]. But no preventive effect was found when CDA22 and CD8 were combined. Studies of the molecular processes involved in competition or antagonism may be required to provide an adequate reason for such findings. Unlike vertebrates with immune memory that quickly identifies different pathogens through antigens and develop effectors and memory cells by clonal expansion, the survival of non-adaptive invertebrates against microbial pathogens with a generation time interval of only a few minutes has been put into question under current evolution theory. Recently, research on increased immunity in invertebrates following the use of vaccine support suspected adaptive immune life [67-68]. Immune priming is a two-stage vaccine procedure in which pathogens are injected into the host system preceded by a secondary vaccination or injection of the same pathogen attack. In Crustaceans, primary priming in L. vannamei resulted in strong phagocytic activity against WSSV following the introduction of WSSV recombinant viral protein within Bacillus subtilis spores. Enhanced immunity to bacterial infections has also been found on both post-larvae and L. juveniles [69]. More study findings concentrate on $V$. parahaemolyticus vaccine development-inducing AHPND. Because shrimps lack an adaptive immune system, passive immunity may theoretically shield shrimps with different egg yolk powders (IgY) from vibriosis by oral administration. In vitro tests showed that it could prevent $V$. parahaemolyticus and $V$. harveyi [70]. In another study have performed this form of passive immunization that showed the unique IgY effectively inhibited $V$. parahaemolyticus growth and provided passive immunity to shrimps [71-72]. As well since toxins A and B of $V$. parahaemolyticus can cause AHPND, monoclonal antibodies to toxins $\mathrm{A}$ and $\mathrm{B}$ have been produced and these monoclonal antibodies can be used to detect the toxins by dot blotting [73-74]. Although the monoclonal antibodies produced have been shown to be successful in detecting toxins A and B and as a therapeutic agent, they are not yet shown to be successful against AHPND as a treatment/therapeutic agent. As of now, commercial shrimp vaccines against AHPND are no longer available. But many studies have attempted to use the $V$. parahaemolyticus antigens to develop a vaccine for this 
pathogenic bacterium [75-76]. Some experiments used anti-Pir A-like toxin IgY in feeds and demonstrated passive AHPND vaccination [77]. The vaccine production against $V$. parahaemolyticus is the deficiency or shortcoming which needs to be tackled. Improvement against AHPND vaccines is a major concern as more studies are required to identify the underlying mechanisms and pathogenesis of the epidemic to understand the disease better. Receptors, toxins, or genes responsible for the virulence of the disease combined with current knowledge and available techniques could accelerate the studies of the vaccines and further the studies of AHPND.

\section{Conclusion}

After the outbreak of AHPND in China in 2009, preventive steps to contain and eliminate the disease started and were imposed to investigate the Pir A and Pir B-like receptors since association processes with the host species to infect the hepatopancreases. Hepatopancreas should be the target tissue in this disease according to current research; mass mortality (up to 100 percent) reported this disease within 30 days after stocking. The $V$. parahaemolyticus stimulates the Rho pathway by an unexplained mechanism. Several PCR studies have been developed and manufactured till now for rapid diagnosis of this disease. This PCR includes the primers AP1, AP2, and/or AP3 to identify different acute genes in the bacterial genome. After all, a thorough understanding of these mechanisms could allow us to use novel and precise strategies required to prevent or at least minimize the effects of shrimp diseases. Since shrimps lack a vital adaptive immune response to combat infectious diseases such as AHPND, further studies are required to examine the immune responses of the shrimp and the mechanisms underlying them. This will be crucial to the development of vaccines and therapies for AHPND and other shrimp diseases. For all potential bacterial pairs, including all species of the Orientalis clade (five members), one species in the Harveyi clade ( $V$. parahaemolyticus), and various other strains, study to know and better understand the $V$. parahaemolyticus acquiring plasmid was determined. There were plenty of molecular and various other testing methods developed and applied to prevent AHPND epidemic results, but still, the bigger question is how we can avoid and manage AHPND; therapeutic agent production has the ability to monitor the epidemic and potentially eliminate the disease. However, control mechanisms have begun and been in effect since the occurrence of AHPND in China back in 2009, but still, there is no proper epidemic prevent and control available for eradication.

\section{Funding}

This research was supported by the DST Science and Engineering Research Board (SERB), and the Ministry of Ayurveda, Yoga \& Naturopathy, Unani, Siddha and Homoeopathy (AYUSH) India.

\section{Acknowledgments}

This research has no acknowledgment.

\section{Conflicts of Interest}

The authors declare no conflict of interest. 


\section{References}

1. Anjaini, J; Fadjar, M.; Andayani, S.; Agustin, I.; Bayu, I. Histopathological in Gills, Hepatopancreas and Gut of White Shrimp (Litopenaeus vannamei) Infected White Feces Disease (WFD). ResJ L Sci 2018, 5, 183-194, https://doi.org/10.21776/ub.rjls.2018.005.03.6.

2. Bernal, M.G.; Marrero, R.M.; Campa-Córdova, Á.I.; Mazón, S.J.M. Probiotic effect of Streptomyces strains alone or in combination with Bacillus and Lactobacillus in juveniles of the white shrimp Litopenaeus vannamei. Aqua Inter 2017, 25, 927-939, https://doi.org/10.1007/s 10499-016-0085-y.

3. Kewcharoen, W.; Srisapoome, P. Probiotic effects of Bacillus spp. from Pacific white shrimp (Litopenaeus vannamei) on water quality and shrimp growth, immune responses, and resistance to Vibrio parahaemolyticus (AHPND strains). Fish Shellf immu 2019, 94, 175-189, https://doi.org/10.1016/j.fsi.2019.09.013.

4. Joshi, J.; Srisala, J.; Sakaew, W.; Prachumwat, A.; Sritunyalucksana, K.; Flegel, T.W.; Thitamadee, S. Identification of bacterial agent (s) for acute hepatopancreatic necrosis syndrome, a new emerging shrimp disease. S J Sci Tech 2014, 21, 315-320, https://doi.org/10.14456/sjst.2014.33.

5. Tandel, G.M.; John, K.R.; George, M.R.; Jeyaseelan, M.P. Current status of viral diseases in Indian shrimp aquaculture. Acta virol 2017, 61, 131-137, https://doi.org/10.4149/av_2017_02_01.

6. Arulmoorthy, M.P.; Anandajothi, E.; Vasudevan, S.; Suresh, E. Major viral diseases in culturable penaeid shrimps: a review. Aqua Int 2020, 28, 1939-1967, https://doi.org/10.1007/s10499-020-00568-3 .

7. Leobert, D.; Cabillon, N.A.R.; Catedral, D.D.; Amar, E.C.; Usero, R.C.; Monotilla, W.D.; Calpe, A.T.; Fernandez, D.D.; Saloma, C.P. Acute hepatopancreatic necrosis disease (AHPND) outbreaks in Penaeus vannamei and $P$. monodon cultured in the Philippines. Dis of aqua org 2015, 116, 251-254, https://doi.org/10.3354/dao02919.

8. Shinn, A.P.; Pratoomyot, J.; Griffiths, D.; Trong, T.Q.; Vu, N.T.; Jiravanichpaisal, P.; Briggs, M. Asian shrimp production and the economic costs of disease. Asia Fish Sci $S$ 2018, 31, 29-58, https://doi.org/10.33997/j.afs.2018.31.S1.003.

9. Flegel, T.W. A future vision for disease control in shrimp aquaculture. J of the Wor Aqua Soc 2019, 50, 249266, https://doi.org/10.1111/jwas.12589.

10. Santos, H.M.; Tsai, C.Y.; Maquiling, K.R. A.; Tayo, L.L.; Mariatulqabtiah, A.R.; Lee, C.W.; Chuang, K.P. Diagnosis and potential treatments for acute hepatopancreatic necrosis disease (AHPND); a review. Aqua Int 2020, 28, 169-185, https://doi.org/10.1007/s10499-019-00451-w.

11. Devadas, S.; Banerjee, S.; Yusoff, F.M.; Bhassu, S.; Shariff, M. Experimental methodologies and diagnostic procedures for acute hepatopancreatic necrosis disease (AHPND). Aqua 2019, 499, 389-400, https://doi.org/10.1016/j.aquaculture.2018.06.042.

12. Bossier, V.K.P. Novel plant-based compounds could be useful in protecting shrimp species against AHPND Vibrio parahaemolyticus. J of the Inl Fish Soc of Ind 2019, 3.

13. De-Schryver, P.; Defoirdt, T.; Sorgeloos, P. Early mortality syndrome outbreaks: a microbial management issue in shrimp farming. PLoS Pathog 2014, 10, https://doi.org/10.1371/journal.ppat.1003919.

14. Akazawa, N.; Eguchi, M. Pond sludge and increased $\mathrm{pH}$ cause early mortality syndrome/acute hepatopancreatic necrosis disease (EMS/AHPND) in cultured white shrimp. Born J of Mar Sci and Aqua 2017, 1 .

15. Wang, R.; Zhong, Y.; Gu, X.; Yuan, J.; Saeed, A.F.; Wang, S. The pathogenesis, detection, and prevention of Vibrio parahaemolyticus. Front in microbio 2015, 6, https://doi.org/10.3389/fmicb.2015.00144.

16. Lai, H.C.; Ng, T.H.; Ando, M.; Lee, C.T.; Chen, I.T.; Chuang, J.C.; Mavichak, R.; Chang, S.H.; Yeh, M.D.; Chiang, Y.A.; Takeyama, H.C. Pathogenesis of acute hepatopancreatic necrosis disease (AHPND) in shrimp. Fish \& shellf immu 2015, 47, 1006-1014, https://doi.org/10.1016/j.fsi.2015.11.008.

17. Kondo, H.; Van, P.T.; Dang, L.T.; Hirono, I. Draft genome sequence of non-Vibrio parahaemolyticus acute hepatopancreatic necrosis disease strain KC13. 17.5, isolated from diseased shrimp in Vietnam. Gen anno 2015, 3, https://doi.org/10.1128/genomeA.00978-15.

18. Han, J.E.; Mohney, L.L.; Tang, K.F.; Pantoja, C.R.; Lightner, D.V. Plasmid mediated tetracycline resistance of Vibrio parahaemolyticus associated with acute hepatopancreatic necrosis disease (AHPND) in shrimps. Aqua Rep. 2015, 2, 17-21, https://doi.org/10.1016/j.aqrep.2015.04.003.

19. Dong, X.; Bi, D.; Wang, H.; Zou, P.; Xie, G.; Wan, X.; Yang, Q.; Zhu, Y.; Chen, M.; Guo, C.; Liu, Z. pirABvp-bearing Vibrio parahaemolyticus and Vibrio campbellii pathogens isolated from the same AHPNDaffected pond possess highly similar pathogenic plasmids. Front in microbio 2017, 8, https://doi.org/10.3389/fmicb.2017.01859.

20. Yu, L.H.; Teh, C.S.J.; Yap, K.P.; Thong, K.L. Diagnostic approaches and contribution of next-generation sequencing technologies in genomic investigation of Vibrio parahaemolyticus that caused acute hepatopancreatic necrosis disease (AHPND). Aqua Int 2020, 28, 2547-2559, https://doi.org/10.1007/s10499020-00610-4.

21. Kumar, V.; Bels, L.D.; Couck, L.; Baruah, K.; Bossier, P.; Broeck, W.V.D. PirABVP toxin binds to epithelial cells of the digestive tract and produce pathognomonic AHPND lesions in germ-free brine shrimp. Toxins 2019, 11, https://doi.org/10.3390/toxins11120717. 
22. Kumar, R.; Ng. TH.; Wang. HC. Acute hepatopancreatic necrosis disease in penaeid shrimp. Rev in Aqua. 202012 3:1867-80. https://doi.org/10.1111/raq.12414.

23. Rovi, A.Y.; Peters, S.; Harder, J.; Christiane, H.; Astrid, G. Structure and co-occurrence patterns of bacterial communities associated with white faeces disease outbreaks in Pacific white-leg shrimp Penaeus vannamei aquaculture. Sci Rep 2020, 10, https://doi.org/10.1038/s41598-020-68891-6 .

24. Zorriehzahra, M.J.; Banaederakhshan, R. Early mortality syndrome (EMS) as new emerging threat in shrimp industry. Adv Anim Vet Sci 2015, 3, 64-72, https://doi.org/10.14737/journal.aavs/2015/3.2s.64.72 .

25. Srinivas, D.; Venkatrayalu, C. Studies on present problems and prospects of shrimp farming in west Godavari district of Andhra Pradesh, India. Adv Appl Sci Res 2016, 7, 49-54.

26. Salunke, M.; Kalyankar, A.; Khedkar, C.D.; Shingare, M.; Khedkar, G.D. A Review on Shrimp Aquaculture in India; Historical Perspective, Constraints, Status and Future Implications for Impacts on Aquatic Ecosystem and Biodiversity. Rev in Fish Sci \& Aqua 2020, 28, 283-302, https://doi.org/10.1080/23308249.2020.1723058.

27. Anderson, J. L.; Valderrama, D.; Jory, D.; GOAL. Global shrimp production review and forecast. Global Aqua Advo 2017.

28. Wang, R.; Fang, S.; Wu, D.; Lian, J.; Fan, J.; Zhang, Y.; Wang, S.; Lin, W. Screening of a ScFv Antibody that Can Neutralize Effectively the Cytotoxicity of Vibrio parahaemolytucs TLH. Appl Environ Microbio 2012.

29. Kumar,V.; Bels, L.D.; Couck, L.; Baruah, K.; Bossier, P.; Broeck, W.V.D. PirABVP toxin binds to epithelial cells of the digestive tract and produce pathognomonic AHPND lesions in germ-free brine shrimp. Toxins 2019, 11, https://doi.org/10.3390/toxins11120717.

30. Ng, T.H.; Lu, C.W.; Lin, S.S.; Chang, C.C.; Tran, L.H.; Chang, W.C.; Lo, C.F.; Wang, H.C. The Rho signalling pathway mediates the pathogenicity of AHPND causing V. parahaemolyticus in shrimp. Cell Microbio 2018, 20, https://doi.org/10.1111/cmi.12849.

31. Lee, C.T.; Chen, I.T.; Yang, Y.T.; Ko, T.P.; Huang, Y.T.; Huang, J.Y.; Huang, M.F.; Lin, S.J.; Chen, C.Y.; Lin, S.S.; Lightner, D.V. The opportunistic marine pathogen Vibrio parahaemolyticus becomes virulent by acquiring a plasmid that expresses a deadly toxin. Proc of the Nat Aca of Sci 2015, 112, 10798-10803, https://doi.org/10.1073/pnas.1503129112.

32. Dong, X.; Chen, J.; Song, J.; Wang, H.; Wang, W.; Ren, Y.; Guo, C.; Wang, X.; Tang, K.F.; Huang, J. Evidence of the horizontal transfer of pVA1-type plasmid from AHPND-causing $V$. campbellii to nonAHPND V. owensii. Aqua 2019, 503, 396-402, https://doi.org/10.1016/j.aquaculture.2019.01.016.

33. Han, J.E.; Tang, K.F.J.; Aranguren, L.F.; Piamsomboon, P. Characterization and pathogenicity of acute hepatopancreatic necrosis disease natural mutants, pirABvp (-) V. parahaemolyticus, and pirABvp (+) V. campbellii strains. Aqua 2017, 470, 84-90, https://doi.org/10.1016/j.aquaculture.2016.12.022.

34. Kumar, R.; Ng,T.H.; Chang, C.C.; Tung, T.C.; Lin, S.S.; Lo, C.F.; Wang, H.C. Bile acid and bile acid transporters are involved in the pathogenesis of acute hepatopancreatic necrosis disease in white shrimp Litopenaeus vannamei. Cell Microbio 2020, 22, https://doi.org/10.1111/cmi.13127.

35. Gomez-Gil, B.; Soto-Rodríguez, S.; Lozano, R.; Betancourt-Lozano, M. Draft genome sequence of Vibrio parahaemolyticus strain M0605, which causes severe mortalities of shrimps in Mexico. Geno anno $2014,2$.

36. Kondo, H.; Tinwongger, S.; Proespraiwong, P.; Mavichak, R.; Unajak, S.; Nozaki, R.; Hirono, I. Draft genome sequences of six strains of Vibrio parahaemolyticus isolated from early mortality syndrome/acute hepatopancreatic necrosis disease shrimp in Thailand. Geno anno 2014, 2, https://doi.org/10.1128/genomeA.00221-14.

37. Yang,Y.T.; Chen, I.T.; Lee, C.T.; Chen, C.Y.; Lin, S.S.; Hor, L.I.; Tseng, T.C.; Huang, Y.T.; Sritunyalucksana, K.; Thitamadee, S.; Wang, H.C. Draft genome sequences of four strains of Vibrio parahaemolyticus, three of which cause early mortality syndrome/acute hepatopancreatic necrosis disease in shrimp in China and Thailand. Geno Anno 2014, 2, https://doi.org/10.1128/genomeA.00816-14.

38. Dolz, G.; Peña-Navarro, N.; Castro-Vásquez, R.; Vargas, B. Molecular detection of acute hepatopancreatic necrosis disease (AHPND) in Penaeus vannamei shrimps in Costa Rica. Aqua 2020, 523, https://doi.org/10.1016/j.aquaculture.2020.735190.

39. Xiao, J.; Liu, L.; Ke,Y.; Li, X.; Liu,Y.; Pan, Y.; Yan, S.; Wang, Y. Shrimp AHPND-causing plasmids encoding the PirAB toxins as mediated by pirAB-Tn903 are prevalent in various Vibrio species. Scirep 2017, 7, https://dx.doi.org/10.1038\%2Fsrep42177.

40. Liu, L.; Xiao, J.; Xia, X.; Pan, Y.; Yan, S.; Wang, Y. Draft genome sequence of Vibrio owensii strain SH14, which causes shrimp acute hepatopancreatic necrosis disease. Geno anno 2015, 3, https://doi.org/10.1128/genomeA.01395-15.

41. Wechprasit, P.; Panphloi, M.; Thitamadee, S.; Sritunyalucksana, K.; Prachumwat, A. Complete genome sequence of Shewanella sp. strain TH2012, isolated from shrimp in a cultivation pond exhibiting early mortality syndrome. Microbio Reso Anno 2019, 8, https://doi.org/10.1128/MRA.01703-18.

42. Liu, L.; Xiao, J.;Zhang, M.; Zhu, W.; Xia, X.; Dai, X.; Pan, Y.; Yan, S.; Wang, Y. A Vibrio owensii strain as the causative agent of AHPND in cultured shrimp, Litopenaeus vannamei. J of inver patho 2018, 153, 156-164, https://doi.org/10.1016/j.jip.2018.02.005. 
43. Restrepo, L.; Bayot, B.;Arciniegas, S.; Bajaña, L.; Betancourt, I.; Panchana, F.; Muñoz, A.R. PirVP genes causing AHPND identified in a new Vibrio species (Vibrio punensis) within the commensal Orientalis clade. Sci rep 2018, 8, 1-14, https://doi.org/10.1038/s41598-018-30903-X.

44. Sawabe, T.; Kita-Tsukamoto, K.; Thompson, F.L. Inferring the evolutionary history of vibrios by means of multilocus sequence analysis. J of bacter 2007, 189, 7932-7936, https://doi.org/10.1128/JB.00693-07.

45. Theethakaew, C.; Nakamura, S.; Motooka, D.; Matsuda, S.; Kodama, T.; Chonsin, K.; Suthienkul, O.; Iida, T. Plasmid dynamics in Vibrio parahaemolyticus strains related to shrimp Acute Hepatopancreatic Necrosis Syndrome (AHPNS). Inf, Gen and Evol 2017, 51, 211-218, https://doi.org/10.1016/j.meegid.2017.04.007.

46. Dangtip, S.; Sirikharin, R.; Sanguanrut, P.; Thitamadee, S.; Sritunyalucksana, K.; Taengchaiyaphum, S.; Mavichak, R.; Proespraiwong, P.; Flegel, T.W. AP4 method for two-tube nested PCR detection of AHPND isolates of Vibrio parahaemolyticus. Aqua Rep 2015, 2, 158-162, https://doi.org/10.1016/j.aqrep.2015.10.002.

47. Hong, X.; Lu, L.; Xu, D. Progress in research on acute hepatopancreatic necrosis disease (AHPND). Aqua int 2016, 24, 577-593, https://doi.org/10.1007/s10499-015-9948-X.

48. Cruz-Flores, R.; Mai, H.N.; Dhar, A.K. Multiplex SYBR Green and duplex TaqMan real-time PCR assays for the detection of Photorhabdus Insect-Related (Pir) toxin genes pirA and pirB. Mol and cell prob 2019, 43, 20-28, https://doi.org/10.1016/j.mcp.2018.12.004.

49. Liu, L.; Jiang, L.; Yu, Y.; Xia. X.; Pan, Y.; Yan, S.; Wang, Y. Rapid diagnosis of Vibrio owensii responsible for shrimp acute hepatopancreatic necrosis disease with isothermal recombinase polymerase amplification assay. Mol and Cell Prob 2017, 33, 4-7, https://doi.org/10.1016/j.mcp.2017.02.001.

50. Koiwai, K.; Tinwongger, S.; Nozaki, R.; Kondo, H.; Hirono, I. Detection of acute hepatopancreatic necrosis disease strain of Vibrio parahaemolyticus using loop mediated isothermal amplification. J Fish Dis 2016, 39, 603-606, https://doi.org/10.1111/jfd.12387.

51. Koiwai, K.; Kodera, T.; Thawonsuwan, J.; Kawase, M.; Kondo, H.; Hirono, I. A rapid method for simultaneously diagnosing four shrimp diseases using PCR-DNA chromatography method. J Fish Dis 2018, 41, 395-399, https://doi.org/10.1111/jfd.12732.

52. Dang, L.T.; Nguyen, H.T.; Hoang, H.H.; Lai, H.N.; Nguyen, H.T. Efficacy of Rose Myrtle Rhodomyrtus tomentosa Seed Extract against Acute Hepatopancreatic Necrosis Disease in Pacific Whiteleg Shrimp Penaeus vannamei. J Aqua Ani Hea 2019, 31, 311-319, https://doi.org/10.1002/aah.10080.

53. Soonthornchai, W.; Chaiyapechara, S.; Klinbunga, S.; Thongda, W.; Tangphatsornruang, S.; Yoocha, T.; Jarayabhand, P.; Jiravanichpaisal, P. Differentially expressed transcripts in stomach of Penaeus monodon in response to AHPND infection. Deve \& Comp Immu 2016, 65, 53-63, https://doi.org/10.1016/j.dci.2016.06.013.

54. Woraprayote, W.; Pumpuang, L.; Tepaamorndech, S.; Sritunyalucksana, K.; Phromson, M.; Jangsutthivorawat, W.; Jeamsripong, S.; Visessanguan, W. Suppression of white feces syndrome in Pacific white shrimp, Litopenaeus vannamei, using hen egg white lysozyme. Aqua 2020, 521, https://doi.org/10.1016/j.aquaculture.2020.735025.

55. Tinwongger, S.; Thawonsuwan, J.; Kondo, H.; Hirono, I. Identification of an anti-lipopolysaccharide factor AV-R isoform (LvALF AV-R) related to Vp_PirAB-like toxin resistance in Litopenaeus vannamei. Fish \& shellf iтmи 2019, 84, 178-188, https://doi.org/10.1016/j.fsi.2018.10.005.

56. Supungul, P.; Jaree, P.; Somboonwiwat, K.; Junprung, W.; Proespraiwong, P.; Mavichak, R.; Tassanakajon, A. A potential application of shrimp antilipopolysaccharide factor in disease control in aquaculture. Aqua Res 2017, 48, 809-821, https://doi.org/10.1111/are.12925.

57. Visetnan, S.; Supungul, P.; Tassanakajon, A.; Donpudsa, S.; Rimphanitchayakit, V. A single WAP domaincontaining protein from Litopenaeus vannamei possesses antiproteinase activity against subtilisin and antimicrobial activity against AHPND-inducing Vibrio parahaemolyticus. Fish \& Shellf Immu 2017, 68, 341-348, https://doi.org/10.1016/j.meegid.2017.04.007.

58. Zheng, Z.; Aweya, J.J.; Wang, F.; Yao, D.; Lun, J.; Li, S.; Ma, H.; Zhang, Y. Acute Hepatopancreatic Necrosis Disease (AHPND) related microRNAs in Litopenaeus vannamei infected with AHPND-causing strain of Vibrio parahemolyticus. BMC geno 2018, 19, https://doi.org/10.1186/s12864-018-4728-4 .

59. Jha, R.K.; Babikian,Y.H.; Babikian, H.Y.; Le, K.V.; Wisoyo, D.; Srisombat, S.; Jiaravanon, B. Efficacy of natural herbal formulation against acute hepatopancreatic necrosis disease (AHPND) causing Vibrio parahaemolyticus in penaeus vannamei. Vet Med Open J 2016, 2, 1-6, https://doi.org/10.17140/vmoj-2-109.

60. Chaweepack, T.; Muenthaisong, B.; Chaweepack, S.; Kamei, K. The potential of galangal (Alpinia galanga Linn.) extract against the pathogens that cause white feces syndrome and acute hepatopancreatic necrosis disease (ahpnd) in pacific white shrimp (Litopenaeus vannamei). Int $J$ of Bio 2015, 7, https://doi.org/10.5539/ijb.v7n3p8 .

61. Lomelí-Ortega, C.O; Martínez-Díaz, S.F. Phage therapy against Vibrio parahaemolyticus infection in the whiteleg shrimp (Litopenaeus vannamei) larvae. Aqua 2014, 434, 208-211, https://doi.org/10.1016/j.aquaculture.2014.08.018.

62. Jun, J.W.; Han, J.E.; Giri, S.S.; Tang, K.F.; Zhou, X.; Aranguren, L.F.; Kim, H. J.; Yun, S.; Chi, C.; Kim, S.G.; Park, S.C. Phage application for the protection from acute hepatopancreatic necrosis disease (AHPND) in Penaeus vannamei. Ind J of microbio 2018, 58, 114-117, https://doi.org/10.1007/s12088-017-0694-9 . 
63. Bernal, M.G.; Marrero, R.M.; Campa-Córdova, Á.I.; Mazón-Suástegui, J.M. Probiotic effect of Streptomyces strains alone or in combination with Bacillus and Lactobacillus in juveniles of the white shrimp Litopenaeus vannamei. Aqua int 2017, 25, 927-939, https://doi.org/10.1007/s10499-016-0085-y .

64. Chumpol, S.; Kantachote, D.; Nitoda, T.; Kanzaki, H. The roles of probiotic purple non-sulfur bacteria to control water quality and prevent acute hepatopancreatic necrosis disease (AHPND) for enhancement growth with higher survival in white shrimp (Litopenaeus vannamei) during cultivation. Aqua 2017, 473, 327-336, https://doi.org/10.1016/j.aquaculture.2017.02.033.

65. Chandrasekaran, R.; Ashok, Kumar. G.V. Antagonistic Activities of Purple Non-sulfur Bacterial Extracts Against Antibiotic Resistant Vibrio sp. 2011, https://doi.org/10.21161/mjm.23510.

66. Wang, H.; Wang, C.; Tang, Y.; Sun, B.; Huang, J.; Song, X. Pseudoalteromonas probiotics as potential biocontrol agents improve the survival of Penaeus vannamei challenged with acute hepatopancreatic necrosis disease (AHPND)-causing Vibrio parahaemolyticus. Aqua 2018, 494, 30-36, https://doi.org/10.1016/j.aquaculture.2018.05.020.

67. Lin, Y.C.; Chen, J.C.; Morni, W.Z.W.; Putra, D.F.; Huang, C.L.; Li, C.C.; Hsieh, J.F.Vaccination enhances early immune responses in white shrimp Litopenaeus vannamei after secondary exposure to Vibrio alginolyticus. PLoS One 2013, 8, https://doi.org/10.1371/journal.pone.0069722.

68. Netea, M.G.; Joosten, L.A.; Latz, E.; Mills, K.H.; Natoli, G.; Stunnenberg, H.G.; O.Neill, L.A.; Xavier, R.J. Trained immunity: a program of innate immune memory in health and disease. Sci 2016, 352, https://doi.org/10.1126/science.aaf1098.

69. Pope, E. C.; Powell, A.; Roberts, E. C.; Shields, R.J.; Wardle, R.; Rowley, A.F. Enhanced cellular immunity in shrimp (Litopenaeus vannamei) after 'vaccination'. Plos one 2011, 6, https://doi.org/10.1371/journal.pone.0020960.

70. Gao, X.; Zhang, X.; Lin, L.; Yao, D.; Sun, J.; Du, X.; Li, X.; Zhang, Y. Passive immune-protection of Litopenaeus vannamei against Vibrio harveyi and Vibrio parahaemolyticus infections with anti-Vibrio egg yolk (IgY)-encapsulated feed. Int J mol sci 2016, 17, https://doi.org/10.3390/ijms17050723.

71. Gao, X.; Zhang, X.; Sun. J.; Du, X.; Li. X.; Zhang, Y.; Lin, L. Passive protection effect of anti-Vibrio anguillarum IgY-encapsulated feed on half-smooth tongue sole (Cynoglossus semilaevi) against $V$. áanguillarum. Fish \& shellf immu 2016, 56, 483-488, https://doi.org/10.1016/j.fsi.2016.07.041.

72. Hu, B.; Yang, X.; Guo, E.; Zhou, P.; Xu, D.; Qi, Z.; Deng, L. The preparation and antibacterial effect of egg yolk immunoglobulin (IgY) against the outer membrane proteins of Vibrio parahaemolyticus. J of the Sci of Food and Agri 2019, 99, 2565-2571, https://doi.org/10.1002/jsfa.9470.

73. Wangman, P.; Chaivisuthangkura, P.; Sritunyalucksana, K.; Taengchaiyaphum, S.; Senapin, S.; Pengsuk, C.; Sithigorngul, P.; Longyant, S. Development of monoclonal antibodies specific to ToxA and ToxB of Vibrio parahaemolyticus that cause acute hepatopancreatic necrosis disease (AHPND). Aqua 2017, 474, 7581, https://doi.org/10.1016/j.aquaculture.2017.03.039.

74. Nguyen-Phuoc, K.H.; Duong, N.D.; Phan, T.V.; Thi Do, K.Y.; Thi Nguyen, N.T.; Linh Tran, T. Tran-Van, H. Generation and evaluation of polyclonal antibodies specific for ToxA from Vibrio parahaemolyticus causing acute hepatopancreatic necrosis disease (AHPND) in shrimp. Mol Bio Res Comm 2020, 23-32, https://doi.org/10.22099/MBRC.2020.38774.1561.

75. Peng, B.; Lin, X.P.; Wang, S. N.; Yang, M.J.; Peng, X. X.; Li, H. Polyvalent protective immunogens identified from outer membrane proteins of Vibrio parahaemolyticus and their induced innate immune response. Fish \& shellf immu 2018, 72, 104-110, https://doi.org/10.1016/j.fsi.2017.10.046.

76. Peng, B.; Ye, J.Z.; Han, Y.; Zeng, L.; Zhang, J.Y.; Li, H. Identification of polyvalent protective immunogens from outer membrane proteins in Vibrio parahaemolyticus to protect fish against bacterial infection. Fish \& Shellf Iтти 2016, 54, 204-210, https://doi.org/10.1016/j.fsi.2016.04.012.

77. Nakamura, R.; Pedrosa-Gerasmio, I.R.; Alenton, R.R.R.; Nozaki, R.; Kondo, H.; Hirono, I. Anti-PirA like toxin immunoglobulin (IgY) in feeds passively immunizes shrimp against acute hepatopancreatic necrosis disease. $J$ of fish dis 2019, 42, 1125-1132, https://doi.org/10.1111/jfd.13024. 